\title{
【Short Paper】 \\ Heat transfer and thermal deformations in non-contacting face seals
}

\author{
Slawomir BLASIAK*, Jakub Emanuel TAKOSOGLU* and Pawel Andrzej LASKI* \\ *Kielce University of Technology, \\ Faculty of Mechatronics and Machine Design, \\ Department of Mechanical Engineering and Metrology, \\ al. Tysiaclecia Panstwa Polskiego 7, 25-314, Kielce, Poland \\ E-mail: sblasiak@tu.kielce.pl
}

Received 2 April 2014

\begin{abstract}
The simulations conducted for non-contacting face seals show that performance-related parameters greatly affect the distribution of temperature in the fluid film causing thermal deformations of the sealing rings. The results indicate that the thermal deformations of the rings should be taken into account at the design stage, especially when non-contacting face seals are to be used in high-performance systems. The mathematical model of heat transfer used for the simulations consists of a system of coupled differential equations with partial derivatives, including heat equations and an energy equation with precisely defined boundary conditions. The calculated distributions of temperature were used to determine the values of thermal deformations of the sealing rings.
\end{abstract}

Key words : Mechanical seal, Non-contacting face seal, Heat transfer, Thermal stresses, Thermal deformation

\section{Introduction}

Mechanical seals are crucial elements of most turbomachines, ensuring their high reliability. They are common in pumps, mixers and other industrial equipment. Designed primarily to reduce power loss, they are also responsible for preventing leakage of the fluid to the environment. This can be achieved by maintaining a proper fluid-filled micro-clearance between the mating sealing rings. Seals of this type are called non-contacting face seals.

In recent years, there have been many reports presenting experimental results and solutions to advanced mathematical models describing complex processes of heat transfer and thermoelastic deformations in non-contacting face seals. Most have dealt with heat transfer in the structural elements of mechanical seals, especially those directly responsible for the shape of the radial clearance, i.e. the mating rings separated with a fluid film.

The first studies focused on developing one-dimensional mathematical models to determine the distribution of pressure and temperature in the clearance and heat transfer through the rings (Pascovici and Etsion, 1992). Mathematical models were further developed, as illustrated in Ref. (Luan and Khonsari, 2009c), and the researchers took into account also the roughness of the mating surfaces. Solutions to the simplified one-dimensional models were used to theoretically analyze heat transfer in non-contacting seals.

More advanced thermohydrodynamic and thermoelastohydrodynamic models of non-contacting face seals were presented in Refs. (Tournerie, et al., 2001, Brunetière, et al., 2003a, 2003b). These complex multi-dimensional mathematical models were solved numerically. Then, the investigations dealt with the effect that the clearance geometry, and the properties of the ring materials have on the distribution of temperature in the fluid film and the seal rings.

The work by Thomas (Thomas, et al., 2007) contains a numerical solution to a TEHD model of a gas-lubricated non-contacting face seal. The model analyzes the heat transfer between the fluid film and the surfaces limiting the clearance which undergo thermal strains, considerably affecting the geometry of the radial clearance. 
The studies discussed in Refs. (Luan and Khonsari, 2009a, 2009b) aimed at determining the distributions of temperature in the fluid film taking into account different types of flow of the fluid through the clearance. It is essential to develop more detailed models and verify the results by comparing them with the experimental data in order to understand the mechanisms of heat transfer in non-contacting face seals, and to determine their influence on the dynamics of the entire sealing system.

Because of their specific design and capability to operate under varied conditions, non-contacting face seals are important elements of sealing systems, especially those where high reliability is required. The solution to the complex mathematical model was used to perform a series of analyses the aim of which was to determine the effect of selected parameters on the changes in the temperature fields in the elements of the non-contacting face seal and calculate the thermal deformations of the rings.

\section{Heat transfer model}

The main design assumption concerning non-contacting face seals is to maintain the fluid-filled microclearance separating the mating rings. However, by properly adjusting its height, we can substantially reduce power loss and the heat flux generated in the fluid film, or minimize leakage, as defined by the respective standards. Prevention of large heat fluxes is particularly important, for instance, in machines and devices used in the food processing industry, where an elevated temperature can be a factor contributing to the occurrence of physical and chemical transitions in the processed products, making them unfit for human consumption.

The typical non-contacting face seal consists of two rings: the stator, flexibly mounted in the casing, and the rotor, rotating with the shaft of the rotary machine. The reliability and failure-free operation of non-contacting face seals is dependent on many factors, including heat transfer conditions and thermal deformations. Generally, it is assumed that the heat flux generated in the fluid film is transferred to the sealing rings and then through convection to the surrounding fluid being in contact with the rings on the process side.

The flow of the fluid through the radial clearance as well as the heat transfer between the clearance and the sealing rings are phenomena that can be described using a mathematical model composed of a system of cross-correlated differential equations with partial derivatives and pre-determined initial and boundary conditions necessary for their correct solution.

Mathematical models developed for non-contacting face seals require certain simplifying assumptions, such as those described in Ref. (Zhou, et al., 2007):

- the physical phenomena are axisymmetric,

- the flow through the radial clearance is pre-determined,

- the liquid has Newtonian properties and is incompressible,

- the mass forces for a small Reynolds number $(\operatorname{Re}<800)$ are negligible.

With these simplifications it is possible to mathematically describe the phenomena occurring in the non-contacting face seal and then to solve the problems analytically or numerically.

\subsection{Basic assumptions on the seal geometry and performance}

The geometry- and performance-related parameters to be used to solve the mathematical model of the non-contacting face seal are presented in Table 1.

Table 1. Geometry- and performance-related parameters.

\begin{tabular}{|l|c|l|c|}
\hline \multicolumn{2}{|c|}{ Geometry-related parameters } & \multicolumn{2}{c|}{ Performance-related parameters } \\
\hline Inner radius $r_{i}$ & $0.040[\mathrm{~m}]$ & Angular velocity $\omega$ & $500[\mathrm{rad} / \mathrm{s}]$ \\
\hline Outer radius $r_{o}$ & $0.045[\mathrm{~m}]$ & Nominal clearance height $h_{o}$ & $1 \times 10^{-6}[\mathrm{~m}]$ \\
\hline Thickness of the rings $L^{s}$ and $L^{r}$ & $0.005[\mathrm{~m}]$ & Fluid temperature $T_{o}$ & $20\left[{ }^{\circ} \mathrm{C}\right]$ \\
\hline
\end{tabular}




\begin{tabular}{|l|c|l|c|}
\hline Fluid density $\rho$ & $999.8\left[\mathrm{~kg} / \mathrm{m}^{3}\right]$ & Fluid specific heat $C_{p}$ & $4189.9[\mathrm{~J} / \mathrm{kg} \mathrm{K}]$ \\
\hline Thermal conductivity $\lambda^{f}$ & $0.65[\mathrm{~W} / \mathrm{m} \mathrm{K}]$ & $\begin{array}{l}\text { Free convection coefficient } \\
\text { (water) } \alpha\end{array}$ & $18000\left[\mathrm{~W} / \mathrm{m}^{2} \mathrm{~K}\right]$ \\
\hline Dynamic viscosity & $0.001[\mathrm{~Pa} \mathrm{~s}]$ & Dimensional coefficient $b$ & $0.0175\left[1 /{ }^{\circ} \mathrm{C}\right]$ \\
\hline
\end{tabular}

Table 2 shows parameters describing some of the properties of the materials used for the seal rings.

For example, the properties of ceramic materials were taken into account in the numerical calculations presented in Ref. (Sommers, et al., 2010; Takosoglu, et al., 2009; Takosoglu, et al., 2012).

Table 2. Properties of the materials used for the rings.

\begin{tabular}{|c|c|c|c|c|}
\hline & $\begin{array}{c}\text { Young's modulus } \\
E\end{array}$ & $\begin{array}{c}\text { Poisson ratio } \\
v\end{array}$ & $\begin{array}{c}\text { Thermal } \\
\text { conductivity } \lambda\end{array}$ & $\begin{array}{c}\text { Thermal expansion } \\
\tau\end{array}$ \\
\hline $\begin{array}{c}\text { Stainless steel } \\
\text { (rotor) }\end{array}$ & $204[\mathrm{GPa}]$ & 0.3 & $16.4[\mathrm{~W} / \mathrm{m} \mathrm{K}]$ & $15.9 \cdot 10^{-6}\left[1 /{ }^{\circ} \mathrm{K}\right]$ \\
\hline $\begin{array}{c}\text { Resin-impregnated } \\
\text { carbon } \\
\text { (stator) }\end{array}$ & $24[\mathrm{GPa}]$ & 0.12 & $10[\mathrm{~W} / \mathrm{m} \mathrm{K}]$ & $4.9 \cdot 10^{-6}\left[1{ }^{\circ} \mathrm{K}\right]$ \\
\hline
\end{tabular}

The model of a non-contacting face seal involves solving a complex system of cross-coupled differential equations with partial derivatives representing:

- the Reynolds equation,

- the energy equation,

- the heat equations for both sealing rings,

- the equations of thermo-elasticity.

To simultaneously solve the equations and determine such parameters as the distribution of pressure in the radial clearance, the distributions of temperature in the rings, and the thermal deformations, it is necessary to take into account a number of boundary conditions.

The solution of the thermohydrodynamic model was described and presented in our previous work (Blasiak, et al., 2013).

In this paper, the heat transfer model was extended, assuming that forced convection occurs between the rotor and the surrounding fluid. Attention was also paid to thermal deformations resulting from different distributions of temperature in the sealing rings cross-sections. It should be emphasized that the height of the radial clearance in the non-contacting face seal operating under specified conditions has a significant effect on the leakage and power loss. The height of the clearance in the radial direction can be considerably different from the value defined in the design calculations.

The shape of the radial clearance is dependent on numerous factors, including the wear of the rings caused by unstable operation of the seal and/or the mechanical or thermal deformations of the rings. The deformations that may occur during the machine operation vary, according to the physical properties of the materials used for the sealing rings, such as thermal conductivity and the thermal expansion coefficient, as well as the heat transfer conditions related to the specific shape of the rings.

While solving the presented model, we also assumed forced convection at the interface between the rotor and the surrounding fluid. For the flexibly mounted stator, which it does not perform a rotary motion, the convection coefficient $\alpha$ was assumed to be constant, like in Ref. (Brunetière, et al., 2003a). For the other ring, which rotates with the machine shaft, the convection coefficient $\alpha$ was calculated using the Becker correlation, like in Ref. (Lebeck,

1991): $\alpha=0.133 \operatorname{Re}_{D}{ }^{2 / 3} \operatorname{Pr}^{1 / 3} \frac{\lambda^{f}}{D}$, where $D$ denotes the outer diameter of the seal and $\operatorname{Re}_{D}$ is the Reynolds number 
based on this diameter. The parameters $\lambda^{f}$ and $\operatorname{Pr}$ are the thermal conductivity and the Prandtl number of the fluid, respectively.

The Reynolds and Prandtl numbers are described as: $\operatorname{Re}_{D}=\frac{\omega D^{2} \rho}{\mu}$ and $\operatorname{Pr}=\frac{C_{p} \mu}{\lambda^{f}}$.

\section{Thermoelastic problem}

The term thermoelasticity refers to a wide range of phenomena but it has been generalized to the classical theories of elasticity and thermal conductivity. This section will cover the basic equations for a uniform isotropic body. In the case considered, the heating of the surfaces of the rings is non-uniform due to changes in the temperature of the fluid, which, in consequence, cause deformations of these structural elements. The differences in the fluid temperature are responsible for the occurrence of strains $\varepsilon_{i j}$ and stresses $\sigma_{i j}$ in the sealing rings, see Ref. (Noda, et al., 2003):

$$
\sigma_{i j}=2 \vartheta \varepsilon_{i j}+(\lambda e-\beta \tau) \delta_{i j} \quad(i, j=1,2,3)
$$

where the Kronecker symbol is defined as $\delta_{i j}=\left\{\begin{array}{ll}1 & \text { for } i=j \\ 0 & \text { for } i \neq j\end{array}\right.$,

Using the equations of equilibrium:

$$
\sigma_{j i, j}+F_{i}=0 \quad(i, j=1,2,3)
$$

We can write the equations of displacements in the general form as:

$$
\vartheta \nabla^{2} u_{i}+(\lambda+\vartheta) u_{k, k i}-\beta \theta_{, i}+F_{i}=0, \text { where: } \beta=\frac{\tau E}{(1-2 v)} .
$$

The values of coefficients $E$ and $v$ are given in Table 2 .

We also assumed that there were no external forces acting on the rings. Thus, $F_{i}=0$ in Eq. (2). By determining the displacements, we were able to predict the changes in the shape of the surfaces of the sealing rings, and accordingly, the geometry of the radial clearance.

The strains of the sealing rings were established with a commercially available system for numerical calculations based on the finite element method. The calculations were conducted using the analytically established distributions of temperature.

\section{Results of the numerical calculations}

The numerical calculations were performed using the mathematical model of the non-contacting face seal presented above. The distributions of temperature were determined on the basis of the relationships presented in Section 2, while the thermal deformations were established numerically applying a special FEM-based program.

The general function describing the shape of the radial clearance was represented in the form of relationship.

$$
h=h(r)=h_{o}+h^{r}(r)-h^{s}(r)
$$

The function of the clearance height (in the model presented) is dependent on the nominal clearance height $h_{o}$ and the geometry of the faces of the rings. A change in the shape of the faces, being the effect of temperature fields, was 
described with the functions $h^{s}(r)$ and $h^{r}(r)$ for the stator and the rotor, respectively. Determining these relationships and including them in the general equation (3) enables us to recalculate the whole model and determine the distributions of temperature in the sealing rings and the fluid film for a clearance geometry taking into account thermal deformations.

\subsection{Influence of the changes in the clearance height}

Fig. 1 shows spatial distributions of temperature in the cross-sections of the stator, the film and the rotor. The heights and radii of the two rings and the clearance height are presented in a non-dimensional form, whereas the distributions of temperature for each of the elements are represented on a regular calculation mesh (10x10 points).
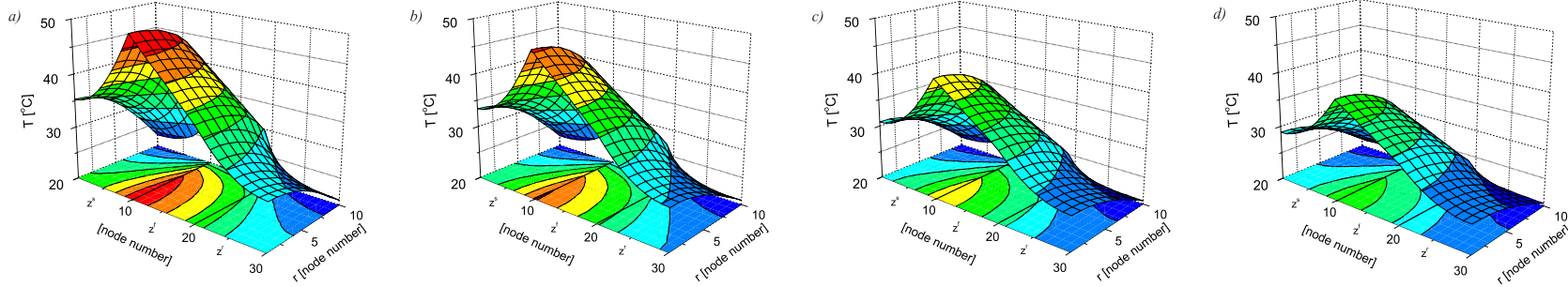

Fig. 1. Distributions of temperature in the fluid film and the sealing rings

a) $h_{o}=1 \cdot 10^{-6}[\mathrm{~m}]$, b) $h_{o}=2 \cdot 10^{-6}[\mathrm{~m}]$, c) $h_{o}=3 \cdot 10^{-6}[\mathrm{~m}]$, d) $h_{o}=4 \cdot 10^{-6}[\mathrm{~m}]$

The maximum temperature is observed at the stator-fluid interface, where the friction between the fluid particles and the non-moving surface of the stator is the highest. Energy Equation, describing the distribution of the heat flux generated in the fluid film, and Fig. 1, showing the distributions of temperature in the fluid film and the sealing rings, suggest that the heat flux can be reduced by increasing the clearance height. This will lead to a decrease in friction and power loss, but may also result in higher leakage, which is definitely undesirable.
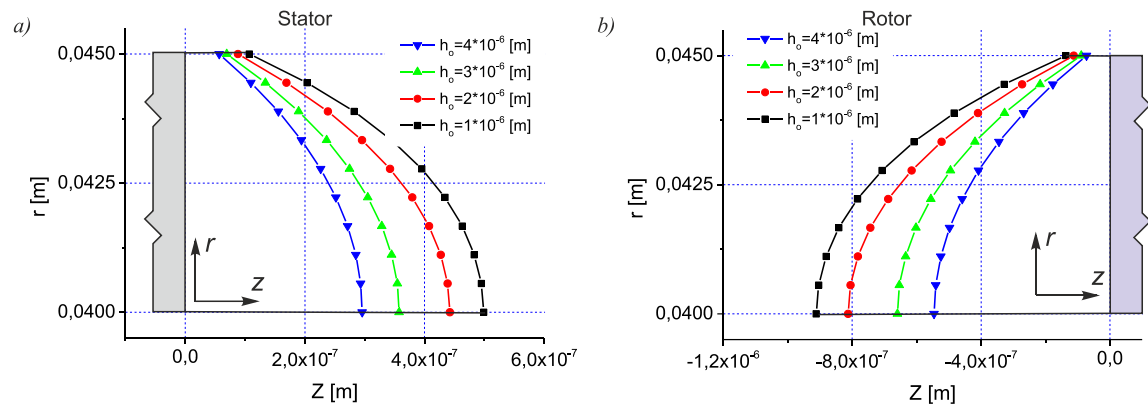

Fig. 2. Deformations due to changes in temperature according to the nominal clearance height

Figure 2 shows the thermal deformations of the sealing rings caused by the changes in the temperature of the fluid in the clearance with a pre-determined height. For the stator, which is made of resin-impregnated carbon, the maximum deformation (at $r=r_{i}$ and $h_{o}=1 \cdot 10^{-6}[\mathrm{~m}]$ ) is almost half the value of that recorded for the rotor. We can notice that the largest deformations occur at points where the temperature reaches a maximum.

\subsection{Influence of the changes in the angular velocity}

Angular velocity is one of the most important parameters to have direct influence on the distribution of pressure in the fluid film as well as the value of the heat flux generated in the clearance. The 3-D diagrams below show distributions of the temperature fields for the angular velocity $\omega$ in the range 200-500 [ $\mathrm{rad} / \mathrm{s}]$. 

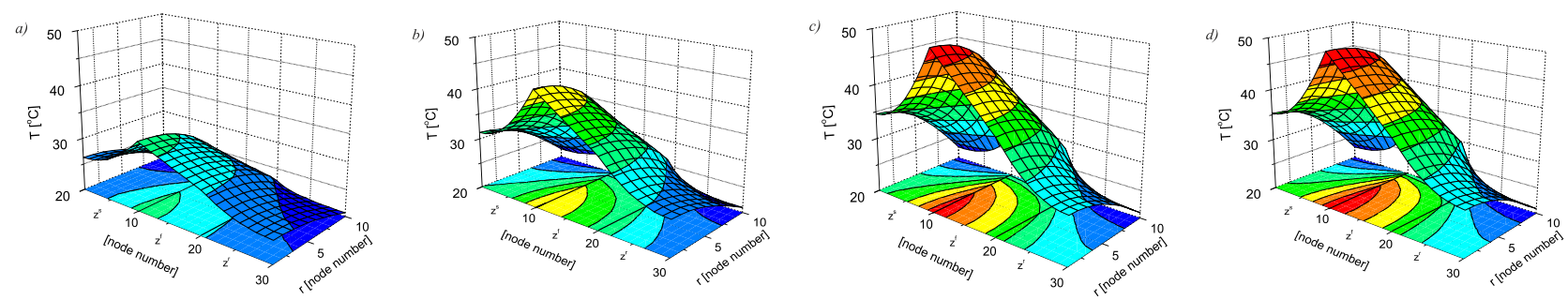

Fig. 3. Distributions of the temperature in the fluid film and the seal ring

a) $\omega=200[\mathrm{rad} / \mathrm{s}]$, b) $\omega=300[\mathrm{rad} / \mathrm{s}]$, c) $\omega=400[\mathrm{rad} / \mathrm{s}]$, d) $\omega=500[\mathrm{rad} / \mathrm{s}]$

From the results illustrated in Fig. 3, we can see that angular velocity has a considerable effect on the changes in the distribution of temperature both in the fluid film and the mating sealing rings. A change in the angular velocity from $\omega=200[\mathrm{rad} / \mathrm{s}]$ to $\omega=500[\mathrm{rad} / \mathrm{s}]$ leads to an almost double increase in the maximum temperature of the fluid film.

This can be explained by an increase in the friction resistance (tangential stress in the fluid), and, accordingly, a rise in the heat flux generated in the clearance, both contributing to thermal deformations of the seal rings.
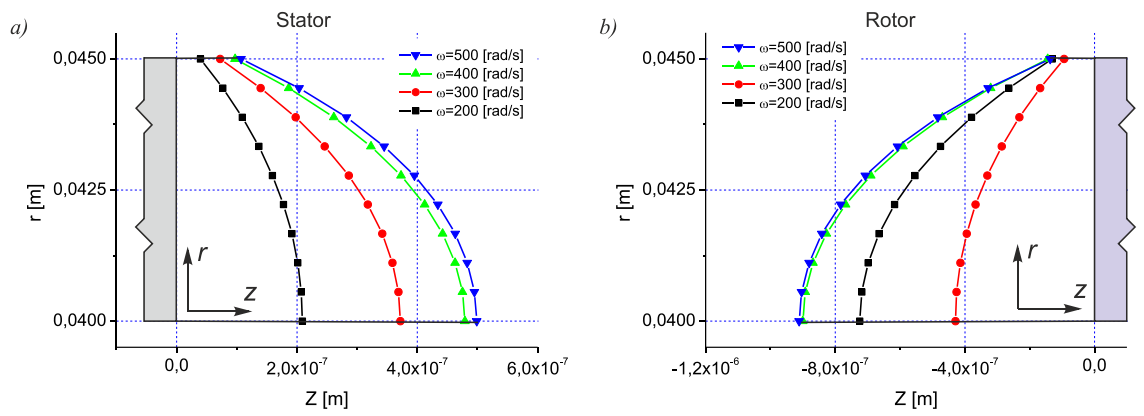

Fig. 4. Deformations due to changes in temperature according to angular velocity.

The above diagrams (Fig. 4) show that, for the assumed model and geometry- and performance-related parameters, the surface deformations at 400 and 500 [rad/s] are almost identical. It should be noted that the maximum deformation of the stator is approximately the same as the nominal clearance height. The results confirm that thermal deformations of the rings should not be neglected as this would cause a considerable simplification of the mathematical model of the non-contacting face seal.

\section{Discussion}

As is frequently emphasized, non-contacting face seals are vital elements of many machines and devices. They are used in virtually all industries to suit many different operating and environmental conditions. Their main function is to maintain leak tightness, which requires forces acting on the rings to remain in equilibrium. The internal hydrostatic and hydrodynamic forces need to be calculated at the design stage to conform to the conditions that the seal will operate in. This equilibrium of forces is easy to disturb, for example, by changes in pressure on the process side, unsuitable angular velocity, or, as is the case described in this paper, by thermal deformations of the surfaces of the rings and, accordingly, considerable changes in the shape of the radial clearance. There exists a direct relationship between the geometry of the radial clearance and the equilibrium of the forces acting on the rings, the leakage and the power loss in the seal. The thermal deformations in the form of changes in the clearance geometry may lead to improper operation of the seal and, in consequence, failure of the machine. Estimating the temperature and thermal deformations at the design stage will enable us to prevent excessive wear of the surfaces of the sealing rings and an uncontrolled increase in leakage or power loss. 


\section{Conclusions}

The paper has dealt with a mathematical model describing heat transfer and thermal deformations in a non-contacting face seal with a flexibly mounted stator. The analysis has focused on the effect of performance-related parameters, including nominal clearance height and angular velocity, on the distributions of temperature in the fluid film and sealing rings, and the thermal deformations of the sealing rings, which is particularly important when the non-contacting face seal is to be used in a fluid flow machine. The simulation results indicate that the non-uniform distribution of temperature resulting from the character of the heat flux is responsible for the deformations of the sealing rings. These deformations should be taken into consideration when heat transfer phenomena at the fluid-ring interface are analyzed. The height of the radial clearance, or more specifically, its changes along the radius, affect the TEHD model of the non-contacting face seal. It can be concluded that models describing thermal deformations of sealing rings should be taken into account at the design phase when non-contacting face seals are to be used in turbomachines.

\section{Nomenclature}

$b$-dimensional coefficient $\left[1 /{ }^{\circ} \mathrm{C}\right]$, for water $b=0.0175$,

$C_{p}$ - specific heat of the fluid,

$e$ - dilatation $e=\varepsilon_{k k}$,

$h_{o}$ - nominal clearance height,

$h^{r}(r), h^{s}(r)$ - functions describing the surface topographies of the rotor and the stator, respectively,

$r_{i}$ - inner radius,

$T$ - absolute temperature,

$T^{f}$ - fluid temperature,

$T_{m}$ - average temperature of the fluid in the clearance,

\section{Greek symbols}

$\alpha-$ free convection coefficient,

$\beta$ - taper angle,

$\lambda, \vartheta-$ Lame constants, which are $\lambda=\frac{v E}{(1+v)(1-2 v)}$ and $\vartheta=\frac{E}{2(1+v)}$, respectively,

$\lambda^{f}-$ heat transfer coefficient for the fluid,

$\lambda^{s}, \lambda^{r}-$ heat transfer coefficients for the stator and the rotor, respectively

$\rho$ - density,

$\mu$-dynamic viscosity, 


\section{References}

Blasiak, S., Laski, P. A. and Takosoglu, J. E., Parametric analysis of heat transfer in non-contacting face seals, International Journal of Heat and Mass Transfer, Vol.57, No.1, (2013), pp. 22-31, DOI:10.1016/j.ijheatmasstransfer.2012.09.058.

Brunetière, N., Tournerie, B. and Frêne, J., TEHD Lubrication of Mechanical Face Seals in Stable Tracking Mode: Part 1-Numerical Model and Experiments, Journal of Tribology ASME, Vol.125, No.3, (2003a), pp. 608-616, DOI:10.1115/1.1510885.

Brunetière, N., Tournerie, B. and Frêne, J., TEHD Lubrication of Mechanical Face Seals in Stable Tracking Mode: Part 2-Parametric Study, Journal of Tribology ASME, Vol.125, No.3, (2003b), pp. 617-627, DOI:10.1115/1.1510886.

Lebeck, A. O., Principles and design of mechanical face seals, Wiley, New York, xxxiii, 764, (1991).

Luan, Z. and Khonsari, M., Analysis of conjugate heat transfer and turbulent flow in mechanical seals, Tribology International, Vol.42, No.5, (2009a), pp. 762-769, DOI:10.1016/j.triboint.2008.10.011.

Luan, Z. and Khonsari, M., Heat transfer correlations for laminar flows within a mechanical seal chamber, Tribology International, Vol.42, No.5, (2009b), pp. 770-778, DOI:10.1016/j.triboint.2008.10.008.

Luan, Z. and Khonsari, M. M., A thermohydrodynamic analysis of a lubrication film between rough seal faces, Proceedings of the Institution of Mechanical Engineers, Part J: Journal of Engineering Tribology, Vol.223, No.4, (2009c), pp. 665-673, DOI:10.1243/13506501JET456.

Noda, N., Hetnarski, R. B., and Tanigawa, Y., Thermal stresses, 2nd ed., Taylor \& Francis, New York, xiv, 493, (2003).

Pascovici, M. D. and Etsion, I., A Thermo-Hydrodynamic Analysis of a Mechanical Face Seal, Journal of Tribology ASME, Vol.114, No.4, (1992), pp. 639-645, DOI:10.1115/1.2920930.

Sommers, A., Wang, Q., Han, X., T'Joen, C., Park, Y. and Jacobi, A., Ceramics and ceramic matrix composites for heat exchangers in advanced thermal systems-A review, Applied Thermal Engineering, Vol.30, No.11-12, (2010), pp. 1277-1291, DOI:10.1016/j.applthermaleng.2010.02.018.

Takosoglu, J. E., Dindorf, R. F. and Laski, P. A., Rapid prototyping of fuzzy controller pneumatic servo-system, The International Journal of Advanced Manufacturing Technology, Vol.40, No.3-4, (2009), pp. 349-361, DOI:10.1007/s00170-007-1349-5.

Takosoglu, J. E., Laski, P. A. and Blasiak, S., A fuzzy logic controller for the positioning control of an electro-pneumatic servo-drive, Proceedings of the Institution of Mechanical Engineers, Part I: Journal of Systems and Control Engineering, (2012), pp. 1335-1343, DOI:10.1177/0959651812456498.

Thomas, S., Brunetière, N. and Tournerie, B., Thermoelastohydrodynamic Behavior of Mechanical Gas Face Seals Operating at High Pressure, Journal of Tribology ASME, Vol.129, No.4, (2007), pp. 841-850, DOI:10.1115/1.2768086.

Tournerie, B., Danos, J. C. and Frêne, J., Three-Dimensional Modeling of THD Lubrication in Face Seals, Journal of Tribology ASME, Vol.123, No.1, (2001), pp. 196-204, DOI:10.1115/1.1327584.

Zhou, J., Gu, B. and Chen, Y., An Improved Design of Spiral Groove Mechanical Seal, Chinese Journal of Chemical Engineering, Vol.15, No.4, (2007), pp. 499-506. 